\title{
Stabilization of RNA during laser capture microdissection by performing experiments under argon atmosphere or using ethanol as a solvent in staining solutions
}

\author{
MATHIEU CLÉMENT-ZIZA, ${ }^{1}$ ARNOLD MUNNICH, ${ }^{1}$ STANISLAS LYONNET, ${ }^{1}$ FRANCIS JAUBERT, ${ }^{2}$ \\ and CLAUDE BESMOND ${ }^{1}$ \\ ${ }^{1}$ INSERM U781, Faculté de Médecine, Hôpital Necker-Enfants Malades, Université René-Descartes, 75015, Paris, France \\ ${ }^{2}$ Department of Pathology, Faculté de Médecine, Hôpital Necker Enfants-Malades, Université René-Descartes, 75015, Paris, France
}

\begin{abstract}
The combination of laser capture microdissection (LCM) and gene expression experiments allows cell specific expression profiling, which is decisive in cellular transcriptomic exploration. LCM makes possible the isolation of unique cells or group of cells, but maintaining RNA quality during this process is challenging. Several protocols are available for section preparation, but none of those guarantees the integrity of the RNA during microdissection, and operators are recommended to perform LCM during a limited time. We hypothesized that the cause of RNA degradation during the microdissection time is the presence of water rendering endogenous RNase activity possible. We thus developed two methods that stabilize RNA during microdissection time for up to $90 \mathrm{~min}$. The first one consists of performing LCM under an argon atmosphere, thus preventing tissue rehydration; it is compliant with all existing microdissection protocols. The second one is a new fixation and staining method using ethanol as solvent in all preparatory steps to LCM that enhances fixation and dehydration of samples. We assessed several stains in regard of their effect on tissue morphology and RNA integrity and adjusted an ethanolic staining solution of cresyl violet and eosin Y.
\end{abstract}

Keywords: laser capture microdissection; RNA stabilization; argon; ethanolic staining

\section{INTRODUCTION}

During the last decade, gene expression profiling has had a huge impact on biological research. Microarray hybridizations are largely used to study the transcriptome of many different tissues and cell lines (Duggan et al. 1999). However, when the cells to be studied are located inheterogeneous tissue, and therefore, are surrounded by purposeless cells, gene expression analysis of bulk tissue levels or even conceals the specific signature of the particular cell type of interest. Laser capture microdissection (LCM) allows precise microscopic isolation of pure cell population from heterogeneous tissues and subsequent nucleic acids extraction and analysis (Emmert-Buck et al. 1996; SuarezQuian et al. 1999). LCM, therefore, makes cell specific expression profiling possible, which may be decisive in

Reprint requests to: Claude Besmond, INSERM U781, Faculté de Médecine, Hôpital Necker-Enfants Malades, Université René-Descartes, 149 rue de Sèvres, 75015, Paris, France; e-mail: claude.besmond@inserm.fr; fax: 33-1-47833206.

Article published online ahead of print. Article and publication date are at http://www.rnajournal.org/cgi/doi/10.1261/rna.1261708. addressing the function and the specificity of each cell in an in vivo physiological or physiopathological setting (Bonner et al. 1997; Luo et al. 1999; Sgroi et al. 1999). However, RNA degradation constitutes the main drawback of this technique, considering that RNA quality has a major impact on the following gene expression profiling results (Goldsworthy et al. 1999; Copois et al. 2007; Fleige and Pfaffl 2006).

Carrying out LCM experiments for gene expression profiling requires (1) acceptable tissue morphology allowing histological selection of the desirable cell type, (2) preserved integrity, and (3) preserved biological accessibility to the RNA. The use of frozen sections has been shown to maximize the quantity and the quality of the RNA recovery (Hiller et al. 1996; Goldsworthy et al. 1999). Furthermore, the nature of chemical components of histological fixative and staining has been shown to affect RNA integrity and accessibility (Goldsworthy et al. 1999; Wang et al. 2006). Even if several protocols (Goldsworthy et al. 1999; Huang et al. 2002; Mikulowska-Mennis et al. 2002; Mojsilovic-Petrovic et al. 2004) and commercial reagents are available for fixation and staining steps, none of those guarantee the integrity of the RNA during microdissection 
time, and users are recommended to perform LCM during a limited time of, at most, $20 \mathrm{~min}$. This time restriction is often a limiting factor when dealing with a totally isolated cell located in a complex tissue. In such a case, more than $20 \mathrm{~min}$ can be required to search and identify cells of interest in the section.

Our aim was to carry out LCM of glial cells and neurons of the myenteric plexus of the colon. Neurons are surrounded by glial cells in the colon, thus making single cell LCM mandatory. We, therefore, needed a lot of time to identify and precisely isolate 1-20 cells on each slide. A pilot study allowed us to estimate that 45-60 min were required for each slide to perform LCM of 10-20 neurons. As existing protocols do not allow enough microdissection time to meet our needs, we had to develop new methods that enable microdissection for at least $60 \mathrm{~min}$ without RNA degradation. The first consists of performing LCM under argon, and the second is a new fixation and staining method using ethanolic solutions of cresyl violet and eosin Y. Both protocols prevent tissue rehydration that would otherwise restore endogenous RNase activity. These methods stabilize RNA during the microdissection time allowing one to perform LCM experiments during an increasing time up to $90 \mathrm{~min}$ without RNA degradation.

\section{RESULTS}

We first hypothesized that one of the main causes of RNA degradation was the rehydration of tissues due to the humidity in the air during the microdissection time. Therefore, the goal of the first strategy that we developed to limit the RNA degradation was to avoid air exposure of sections during microdissection time by performing the experiment under a neutral gas, i.e., argon. A simple system that delivers an argon flux on the slide has been designed and set up on the microscope. As argon is heavier than air, a light flow of argon delivered above the slide is sufficient to create a local argon environment on its surface. In order to assess the influence of argon on RNA stabilization after the staining procedure, we compared the kinetic of RNA degradation of sections exposed to air versus sections kept under argon under the microscope. Frozen human colon sections were mounted on the same slide and were stained following standard LCM staining procedures (HistoGene LCM Frozen Section Staining Kit, Arcturus). Slides were disposed under the microscope with and without argon. RNA was extracted from section scrapes at different time points and its quality was measured. Sections exposed to the argon flux showed less than $5 \%$ of RNA degradation when kept up to $90 \mathrm{~min}$ under the microscope, whereas $20 \%$ of degradation were reached as of $30 \mathrm{~min}$ without argon (Fig. 1A). Thus, argon
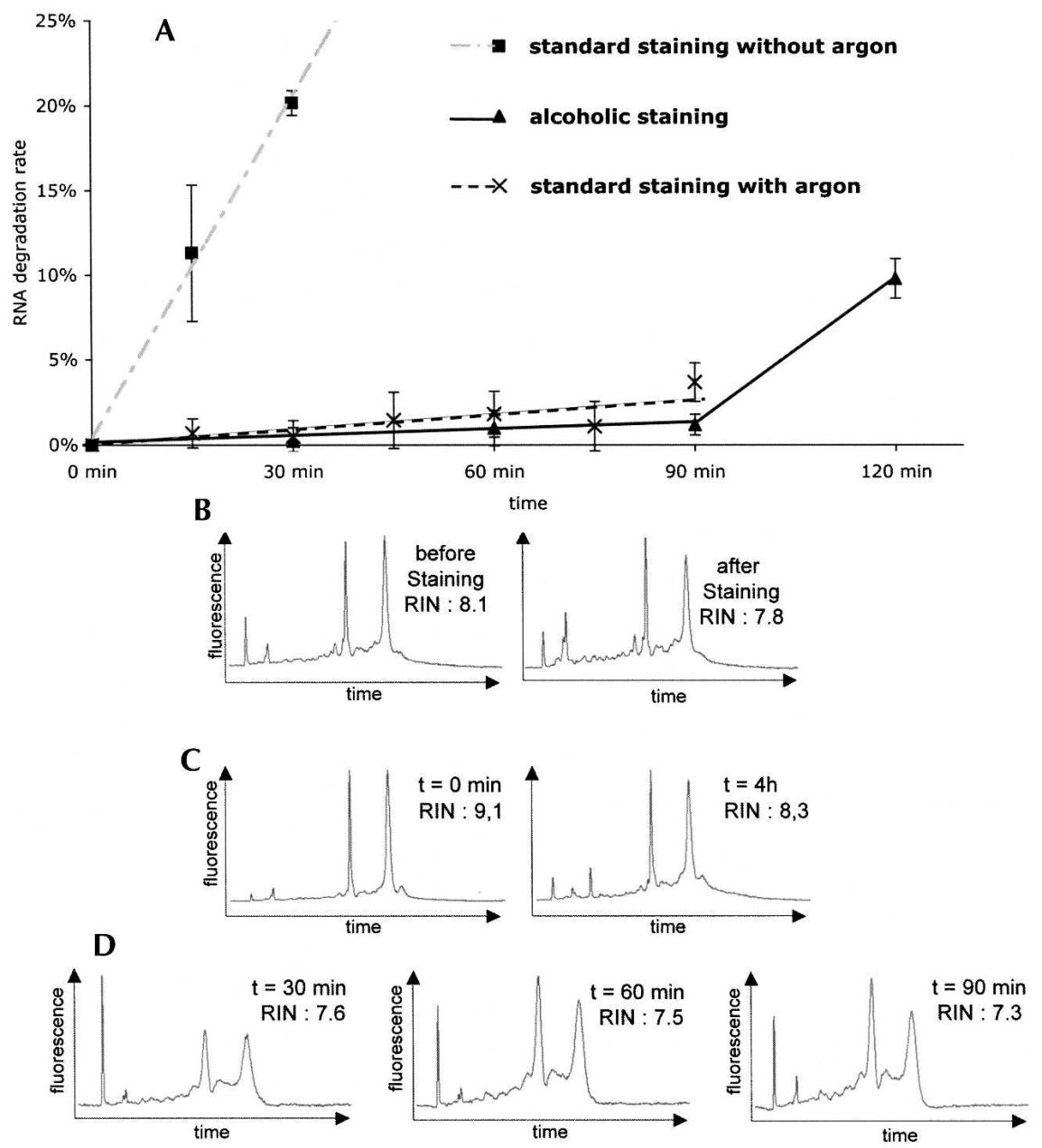

FIGURE 1. RNA integrity along the microdissection process. (A) Degradation of the RNA during the microdissection time. RNA were extracted from section scrapes on a single slide at different time points after staining. Experiments were repeated at least three times. RNA quality was evaluated on Bioanalyser Agilent using the RIN algorithm. The RNA degradation ratio is the average of the ratios of the difference between RIN values of RNA from sections at time point of interest and from section after staining, of RNA from these sections. Performing microdisection under argon or using the ethanolic protocol stabilizes RNA for up to $90 \mathrm{~min}$ after staining. $(B-D)$ Representative Agilent Bioanalyser traces of RNA separations. (B) RNA extracted from stained sections scrapes stored for $4 \mathrm{~h}$ under vacuum. Sections were stained following the standard aqueous protocol. $(C)$ RNA extracted from section scrapes before and after staining using the proposed protocol. (D) RNA extracted from large microdissected patches of cells after $30 \mathrm{~min}, 60 \mathrm{~min}$, and $90 \mathrm{~min}$ under the microscope. Slides were stained following the proposed protocol. 
stabilizes RNA of sections after staining during the microdissection time.

To demonstrate that this stabilization is due to the absence of air and not to the presence of argon, we investigated the degradation of RNA of stained sections kept under vacuum. Two sections were mounted and stained on the same slide to avoid slide effect. RNA from one section was extracted just after staining and RNA of the remaining section was extracted after the slide had been kept under vacuum at room temperature for $4 \mathrm{~h}$. The experiment was repeated five times and the mean of RNA degradation was only $9.5 \%$ (Fig. 1B). Control experiments were performed without vacuum, and RNA was completely degraded when slides were left exposed to air. In addition, we observed that performing LCM under argon does not alter the efficiency of the capture.

The second strategy that we developed to limit RNA degradation during the microdissection time was to enhance fixation, staining, and dehydration efficiency during the slide preparation step. We hypothesized that (1) removal of water during the whole process and (2) stringent dehydration could inhibit or delay rehydration of the tissue during the microdissection time and its subsequent RNA degradation. We developed a new fixation and staining method that relies on alcoholic solutions and ensures the integrity of RNA during microdissection time (up to $90 \mathrm{~min}$ ) while maintaining tissue morphology.

To design this new method, our objectives were to examine the combined effects of fixation and staining on tissue morphology and RNA integrity during the microdissection steps. Previous studies on the fixation step showed that $75 \%$ ethanol is the best fixative (Goldsworthy et al. 1999); in our study, we used $95 \%$ ethanol to minimize the amount of water for the fixation step. In order to limit rehydration of samples during the staining step, we assayed five stains (eosin B, eosin Y, methyl green, cresyl violet, hematoxylin) working at saturation concentration in ethanolic media, and each staining method was analyzed regarding tissue morphology, RNA integrity, and RNA stabilization.

The quality of tissue morphology was evaluated for each stain, alone or in combination, in three independent experiments by the ability to identify myenteric ganglions in the colon and to discriminate neurons and glial cells within ganglions. The preservation of cytoplasmic and nuclear details as well as stain clarity, uniformity, and reproducibility were considered. Eosin B and methyl green, which stain, respectively, the cytoplasm and the nucleus, presented faint colors when used in alcoholic solvent. Haematoxylin stained correctly all nuclei but also the cytoplasm of all myentric plexus cells, inhibiting discrimination between glial and nervous cells. The best results were provided by the use of cresyl violet and eosin Y, which, respectively, stain nucleus and cytoplasm (Fig. 2; Table 1).

The influence of the staining method on RNA was assessed by comparing the quality of total RNA extracted from tissue scrapes on the same slide prior and after fixation/staining steps (experiments have been repeated at least four times). Significant RNA degradation was surprisingly observed when staining solutions containing hematoxylin were used. Eosin Y, methyl green, and cresyl violet stainings did not alter RNA (Table 1). Eosin B and methyl green in ethanolic mediums showed poor histological results. Satisfying results were obtained for the following staining solution: $4 \%$ cresyl violet in $75 \%$ ethanol mixed with $0.5 \%$ eosin $\mathrm{Y}$ in $95 \%$ ethanol freshly at $70: 30(\mathrm{v} / \mathrm{v})$ (Fig. 1C). RNA degradation does not exceed 3.7\% during the staining, and RIN values ranging from 7.6 to 8.0, typically, are obtained from RNA extracted from stained sections.

We assessed the ability of our staining protocol to maintain RNA integrity along time. Therefore several sections were mounted on the same slide in order to avoid slide effects. Sections were stained by cresyl violet and eosin $\mathrm{Y}$ and slides were kept under the microscope. RNA was extracted from section scrapes at different time points up to $120 \mathrm{~min}$. RNA quality was compared at each time point in order to evaluate the kinetics of the RNA degradation (Fig. 1A). Only minor RNA degradation was then observed along time when leaving the slides on the bench for 90 min. This result is dramatic when compared to the fast
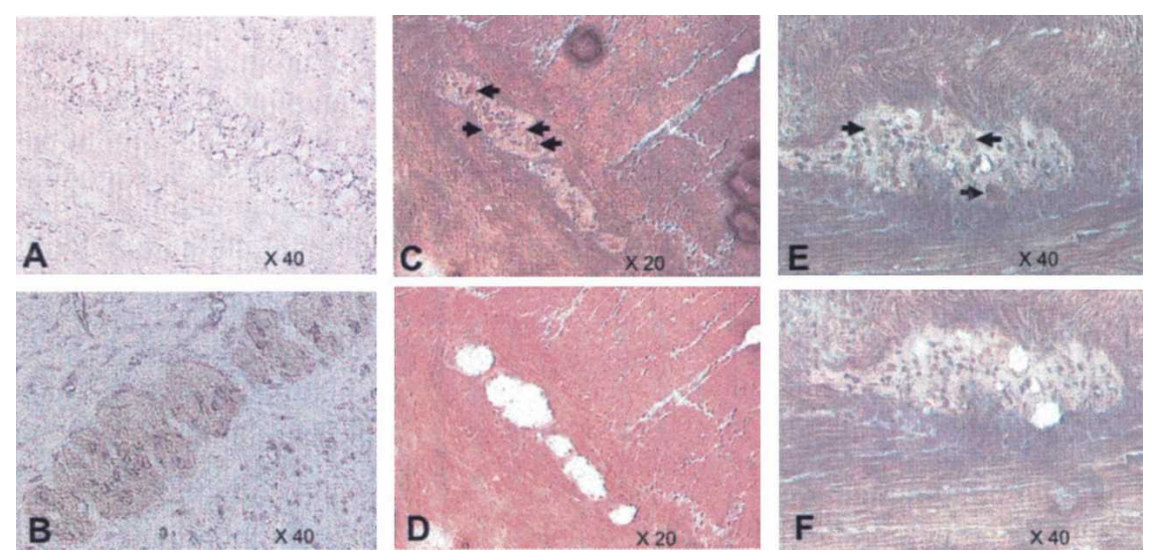

FIGURE 2. Histological staining of frozen sections of human colon. A myenteric ganglion can be seen between the circular and longitudinal muscle layers. All images were captured on a microscope optimized for LCM, viewing frozen sections that had been processed to minimize RNA damage and lacking cover slips. Different alcoholic staining methods were used. Stains of sections are as follows: $(A)$ methyl green and eosin $\mathrm{B} ;(B)$ hematoxylin and eosin $\mathrm{Y} ;(C-F)$ cresyl violet and eosin $Y$. Arrows point to neurones within the ganglion. $C$ and $D$ were captured viewing the same slide before and after the LCM of the total ganglion. $E$ and $F$ were captured viewing the same slide before and after the LCM of nervous cells within the ganglion. 
TABLE 1. Evaluation of tissue and cell morphology and RNA degradation

\begin{tabular}{lccc}
\hline & $\begin{array}{c}\text { Ability to } \\
\text { distinguish } \\
\text { myenteric } \\
\text { ganglions }\end{array}$ & $\begin{array}{c}\text { Ability to } \\
\text { distinguish } \\
\text { nervous cells }\end{array}$ & $\begin{array}{c}\text { RNA } \\
\text { degradation } \\
(\%)\end{array}$ \\
\hline Eosin B & - & - & 9.8 \\
Eosin Y & + & - & 3.7 \\
Methyl green & - & - & 3.9 \\
Hematoxylin & + & - & 33.0 \\
Cresyl violet & - & - & 2.4 \\
Eosin B, methyl green & + & - & $\mathrm{NA}$ \\
Eosin B, cresyl violet & + & ++ & $\mathrm{NA}$ \\
Eosin Y, methyl green & +++ & + & 5.0 \\
Eosin Y, cresyl violet & +++ & +++ & 3.7 \\
\hline
\end{tabular}

Eosin B was prepared at $1 \%$ in $75 \%$ ethanol; Eosin $\mathrm{Y}$ at $0.5 \%$ in 95\% ethanol; Methyl green at $4 \%$ in $75 \%$ ethanol; Cresyl violet at $4 \%$ in $75 \%$ ethanol; Hematoxylin at $10 \%$ in $75 \%$ ethanol. Combinations of stains were prepared by mixing previously described single stain solutions. Experiments were repeated at least four times.

RNA degradation when aqueous staining methods are employed. In order to evaluate the relative implication of staining agent and ethanol medium on stabilization of RNA, the staining solution was replaced by an ethanolic solution without stain, and no difference was observed with or without stain. We conclude that RNA stabilization only depends on the use of an alcoholic staining solution as long as the staining agents employed do not alter RNA.

In order to test the efficiency of our proposed protocol in an LCM condition, we performed microdissection experiments of a large patch of cells at different time points from a single slide on which several sections were mounted. Only minor RNA degradation was observed for an extended microdissection time of up to $90 \mathrm{~min}$ (Fig. 1D). We showed that this protocol also allows efficient single-cell capture by performing LCM of myenteric neurons (Fig. 2).

Captured cell RNA was then used to perform specific RT-PCR on high and low expressed genes (ACTB, VIM, MTHFD1, and TERF1). The RT-PCR products were successfully sequenced and presented no abnormality (Fig. 3). This experiment demonstrates that our protocol maintains biological accessibility to the RNA.

When assaying a combination of the two protocols and as expected, no difference in RNA stabilization was observed when compared to the results obtained with either protocol alone.

\section{DISCUSSION}

High-quality RNA as a starting material is mandatory when carrying out gene expression profiling experiments because degraded RNA results in biased patterns since the kinetics of RNA degradation is RNA species dependent (Copois et al. 2007; Deutscher 2006; Fleige and Pfaffl 2006). How- ever, maintaining the integrity of the RNA during the LCM process is challenging since many steps are performed at room temperature and biological samples encompass RNases. Several sample preparation protocols are available (Goldsworthy et al. 1999; Huang et al. 2002; MikulowskaMennis et al. 2002; Mojsilovic-Petrovic et al. 2004), but none of those were developed to stabilize RNA during the microdissection time. We assessed these protocols and we noticed that RNA quality was decreasing during the time of microdissection, preventing us from performing microdissection experiments for more than 20 min (Fig. 1A). RNA damage thus occurs during the microdissection step, with the probable consequence of loss of representation of genes in expression analysis. Therefore we developed two innovative protocols that prevent the degradation of the RNA during the microdissection time. The first consists of performing LCM under argon, and the second is a new fixation and staining method using ethanolic solutions of cresyl violet and eosin Y. In this study, we demonstrated that both of these LCM methods (1) correctly stain the section, allowing histological selection of the desirable cell type (i.e., neurons of the myenteric plexus of the colon); (2) stabilize RNA during microdissection time up to $90 \mathrm{~min}$; and (3) preserve the integrity of RNA.

The hypothesis we formulated to develop these methods is that RNA degradation during the microdissection could be limited by enhanced and maintained dehydration of the sample sections. Therefore, we developed two strategies: (1) prevent the rehydration of the sections during the microdissection time, and (2) enhance fixation, staining, and dehydration efficiency during the slide preparation step. The results presented here confirm that the absence of water disables the endogenous RNases activity, thus limiting the RNA degradation, as has previously been suggested (Fend et al. 1999).

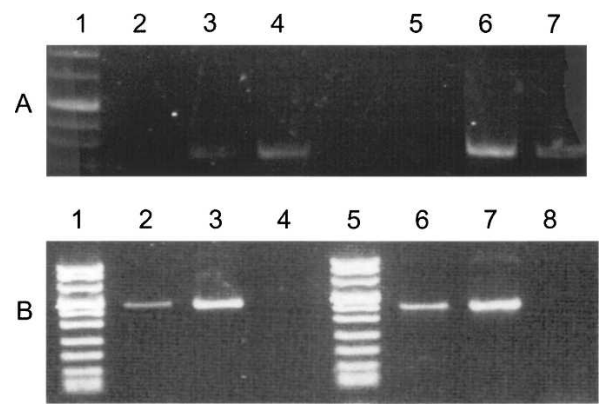

FIGURE 3. RT-PCR products of VIM, ACTB, TERF1, and MTHFD1 sequences. ( $A$, lane 1$)$ Molecular weight markers; (lanes 2,5) water controls; (lanes 3,4) RT-PCR amplification of a 246-bp VIM fragment from microdissected cells and colon tissue respectively; (lanes 6,7) RTPCR amplification of a 222-bp ACTB fragment from colon tissue and microdissected cells, respectively. ( $B$, lanes 1,5$)$ Molecular markers; (lanes 2,3) RT-PCR amplification of a 439-bp TERF1 fragment from microdissected cells and colon tissue, respectively; (lanes 6,7) RT-PCR amplification of a 386-bp MTHFD1 fragment from microdissected cells and colon tissue, respectively; (lanes 4,8 ) water controls. 
In order to limit the rehydration of the tissue during the microdissection time, we have designed a system that delivers argon above the section under the microscope. We have chosen argon because (1) it is heavier than air, thus allowing us to easily create a local argon environment at the surface of the section; and (2) it is an inert gas that does not interact with tissues. Performing the LCM under argon requires the setup of a simple system and is compliant with all existing microdissection protocols (Fig. 4). It can be particularly useful for specific tissue preparation that requires the presence of water (i.e., specific staining or immuno-histochemistry). The results we obtained show that performing LCM under an argon flow stabilizes RNA for $90 \mathrm{~min}$ and does not modify the efficiency of the capture. Neither the preservation of RNA integrity during the microdissection time nor the maintenance of tissue dehydration after section preparation have been studied before.

In order to delay rehydration of the tissue during the microdissection time and its subsequent RNA degradation, we enhanced fixation, staining, and dehydration efficiency during the section preparation step by removing water during the process. To improve the fixation of the tissue, $95 \%$ ethanol has been used instead of $75 \%$ ethanol. Alcoholic staining solutions of cresyl violet and eosin $\mathrm{Y}$ have also been developed. It allows us to (1) identify the cell to be captured and (2) preserve RNA from degradation during microdissection time up to $90 \mathrm{~min}$. The importance of tissue dehydration in LCM has previously been described (Fend et al. 1999; Ball et al. 2002). Although it has been widely used in LCM protocols, the impact of dehydration on RNA stabilization after the section preparation has never been described. The novelty of the approach described here is that no hydration step is performed, allowing an enhanced fixation and dehydration of the tissues compared with the other available section preparation protocols. Indeed, in standard aqueous staining protocols, sections are fixed in a $75 \%$ ethanol solution then

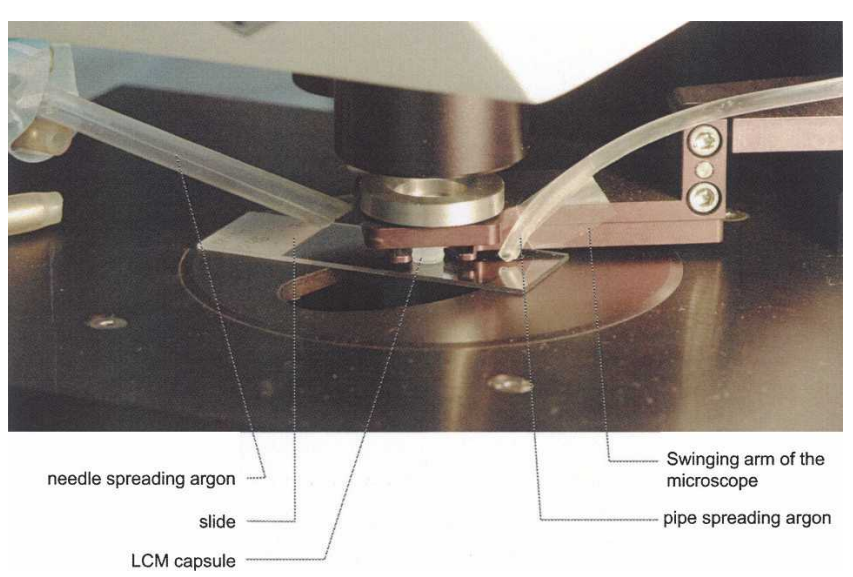

FIGURE 4. Photography of the design and setup of the system that delivers argon flux on the microscope. rehydrated in water before staining. Therefore, the use of stains diluted in alcohol (1) prevents rehydrating the tissue in water, thus limiting the activity of RNases; (2) allows directly fixing sections in $95 \%$ alcohol, as staining rehydration is not necessary; and (3) maximizes the dehydration of the sections. In order to totally dehydrate sections, anhydrous $100 \%$ ethanol and anhydrous xylene were used. As alcohol is highly hygroscopic, it was stored under an argon atmosphere to prevent it from hydration by humidity of the air, and molecular sieves were used to trap water. Xylene was handled with the same carefulness. These method details may be important, as those solvents are used in the final dehydration steps.

Several alcoholic staining solutions were assessed in regard of their effect on tissue morphology and RNA integrity. We noticed that stains that were very efficient when dissolved in water such as hematoxylin and eosin B are faint or poorly resolutive in alcoholic solvent. These results show that the interaction between stains and organelles are solvent dependent. We also observed significant RNA degradation when alcoholic staining solutions containing hematoxylin were used. This result is surprising, considering that hematoxylin dissolved in aqueous solvent is commonly used as staining for LCM experiments (Frost et al. 2001; Michel et al. 2003; Wang et al. 2006; Yang et al. 2006). It may be hypothesized that the interaction between RNA and hematoxylin is solvent dependent or dose dependent, as the minimal concentration of hematoxylin used to stain is a hundred times greater when it is dissolved in alcohol than in water.

When assaying a combination of the two protocols, no difference in RNA stabilization is observed compared to the results obtained with either protocol alone. This may be due to the already high efficiency of each protocol. Moreover, preparing the sample with the alcoholic staining method stabilizes RNA as efficiently as performing LCM under a flow of argon. This may suggest that the better dehydration of the samples delays the time before the rehydration is important enough for the RNases to be activated. This hypothesis could also explain the sudden acceleration of RNA degradation observed after $90 \mathrm{~min}$ when using the ethanolic staining method (Fig. 1A).

The colon is a heterogeneous organ composed of epithelium, muscle, and nervous structures. The staining method we developed provides an unambiguous morphology for all these structures. The cresyl violet and eosin Y staining method could be used for a number of tissues in replacement of the routine hematoxylin and eosin staining in view of performing LCM experiments. This procedure was applied to perform LCM of neurons and glial cells of myenteric nervous plexus. Total RNA was extracted from the microdissected samples and linearly amplified, and Affymetrix Genechip were then successfully hybridized (data not shown).

Overall our results show that dehydration and nonrehydration of the samples are two key points for maintaining RNA integrity during LCM. These approaches are a 
breakthrough for LCM, especially when working with single cells, allowing recovery of high quality RNA while taking time for precise cell selection and microdissection. These might potentially impact the overall quality of cellular gene expression studies using LCM.

\section{MATERIALS AND METHODS}

\section{Preparation of LCM samples}

Surgical colon samples were collected according to standard ethical procedures with informed consent. Samples were frozen in liquid nitrogen without any tissue embedding medium and stored at $-80^{\circ} \mathrm{C}$. Nine micrometer serial frozen sections were cut at $-29^{\circ} \mathrm{C}$ and mounted on a chilled, uncoated microscope glass slide precleaned in a $0.5 \%$ SDS bath and rinsed in three baths of distilled water and one bath of $75 \%$ ethanol. Slides were kept on dry ice and then at $-80^{\circ} \mathrm{C}$ until LCM was completed. All procedures were carried out at room temperature, unless otherwise stated, and usually in the same week as the frozen sectioning.

\section{Aqueous standard staining procedures}

Sections were stained using HistoGene LCM Frozen Section Staining Kit (Arcturus) according to the manufacturer's recommendations.

\section{Alcoholic staining procedures}

For each evaluated stains, the same staining procedures were performed. Slides were removed from dry ice or $-80^{\circ} \mathrm{C}$ and fixation was directly performed without allowing sections to defrost by incubating slides $30 \mathrm{sec}$ into $95 \%$ ethanol. Staining solution was then directly applied to the section and incubated for $20-30 \mathrm{sec}$, followed by rinsing in 95\% ethanol in two steps ( $1 \mathrm{~min}$ each), dehydration in $100 \%$ ethanol in two steps (1 min each), and xylene in two steps (9 min each). Fresh solutions were used for each staining. In order to keep anhydrous 100\% ethanol, stock solution was aliquoted in $250 \mathrm{~mL}$ jars containing freshly activated $3-\AA$ molecular sieves, and each aliquot was stored under argon atmosphere renewed at each use. The same protocol using $4-\AA$ molecular sieves was performed to store xylene.

\section{Staining solutions}

Eosin B, methyl green, cresyl violet, and hematoxylin solution were prepared in ethanol $75 \%$ at high concentration (respectively $1 \%, 4 \%, 4 \%$, and $10 \%$ ) and filtered; commercial eosin $\mathrm{Y}$ at $0.5 \%$ in $95 \%$ ethanol (Sigma-Aldrich) was used. Methyl green, cresyl violet, and hematoxylin stain nuclei whereas eosin $\mathrm{B}$ and eosin $\mathrm{Y}$ stain the cytoplasm. The effect of each stain on RNA degradation has been assessed independently. We also analyzed the histological morphology of all combinations of nucleus and cytoplasm stains that do not degrade RNA. In order to stain within a single step, new staining solutions were obtained by mixing stock alcoholic single stain solutions just before use. The proportion of each stock staining solution in a mix has been adjusted regarding results.

\section{RNA extraction from section scrapes}

RNA was prepared by pipetting $75-100 \mu \mathrm{L}$ of extraction buffer directly onto the tissue section on the glass slide and using the pipette tip to gently scrape the tissue into the buffer, which was then transferred into an RNase-free microcentrifuge tube. RNA was extracted using the PicoPure RNA Isolation Kit (Arcturus) according to the manufacturer's protocol, including on-column DNase treatment (Qiagen).

\section{Laser capture microscopy}

In order to assess the RNA quality after microdissection, large patches of cells covering all the surface of CapSure HS LCM plastic caps (Arcturus) were isolated. PrepStrips (Arcturus) were applied onto the surface of slides prior to the LCM according to the manufacturer's protocol in order to remove dust and to flatten sections. Cells were then lifted from the slide onto the caps using a $30-\mu \mathrm{m}$ spot size of laser at a power of $90 \mu \mathrm{W}$ and a pulse duration of 2.9 msec using a PixCell II LCM system (Arcturus). RNA was then extracted using the PicoPure RNA Isolation Kit (Arcturus) according to the manufacturer's protocol, including on-column DNase treatment (Qiagen). In order to test if our protocol enables the LCM of single cells, myenteric neurons were isolated using a 7.5- $\mu \mathrm{m}$ spot size of laser at a power of $29 \mu \mathrm{W}$ and a pulse duration of $0.8 \mathrm{msec}$.

\section{Argon system for laser capture microscopy}

A system that delivers an argon flux just above the slide has been set up on a PixCell II LCM system. A needle has been fixed on a stand and positioned just above the slide on its left, and a flexible pipe has been mounted on the microscope swinging arm. Those two elements were connected to a bottle of argon (Air products) that delivered gas at a pressure of 0.1 Bar during experiments.

\section{RNA quantification and quality control}

RNA concentrations were evaluated using a Nanodrop ND-1000 spectrophotometer (Nanodrop Technologies). The quality of total RNA extracted from sections scrapes and from microdissected large patches of cells was assessed using an Agilent 2100 bioanalyzer (Agilent RNA6000 PicoChip) and the RIN algorithm (Schroeder et al. 2006). It has been shown that the RIN score was a more reliable and user-independent method for RNA quality assessment than the conventional methods, i.e., spectroscopy and 28S:18S area or intensity ratio (Imbeaud et al. 2005). In order to objectively estimate RNA degradation, we defined the RNA degradation ratio as the average of the ratios of the difference between RIN values of the RNA extracted from the sample in is initial state and from sample in its final state, of the RIN value of the RNA extracted from the sample in is initial state:

$$
R_{\text {degradation }}=\frac{\mathrm{RIN}_{\text {init }}-\mathrm{RIN}_{\text {final }}}{\mathrm{RIN}_{\text {init }}} .
$$

\section{RT-PCR}

Oligonucleotide primers were designed from the ACTB, VIM, MTHFD1, and TERF1 transcript sequences available in GenBank and using the Primer3 software. Primers for ACTB amplicon (222 base pairs [bp]), VIM amplicon (246 bp), MTHFD1 amplicon (386 bp), and TERF1 amplicon (439 bp) are as follows: 
ACTB-F 5' -AGCACAGAGCCTCGCCTTT-3';

ACTB-R 5' -CCCACATAGGAATCCTTCTGACC-3';

VIM-F 5' -CGTACGTCAGCAATATGAAAGTGTG-3'; VIM-R 5'-ACGGCAAAGTTCTCTTCCATTTC-3'; MTHFD1-F 5'-TTGTTGGCCCAGAAGGGTTTGT-3'; MTHFD1-R 5'-AGTGCACTTCACGGCATCAA-3'; TERF1-F 5'-ACAGCTTGCCAGTTGAGAACGA-3'; and TERF1-R 5'-TTGCCGCTGCCTTCATTAGA-3'.

Reverse transcriptions were set up in a reaction volume of $20 \mu \mathrm{L}$ combining $1 \mathrm{ng}$ of total RNA, $50 \mathrm{pmol}$ of random hexamers, 200 $\mu \mathrm{M}$ dNTP, $10 \mathrm{mM}$ DTT, $1 \times$ SuperScript II First-Strand Buffer (Invitrogen), $40 \mathrm{U}$ RNase inhibitor (Invitrogen), and $200 \mathrm{U}$ of SuperScript II (Invitrogen). The reaction was incubated according to the manufacturer's protocol. PCR reactions were set up in a total volume of $25 \mu \mathrm{L}$ containing $2 \mu \mathrm{L}$ of single-stranded cDNA previously obtained, $800 \mathrm{nM}$ of primers, $1 \times$ PCR buffer, $200 \mu \mathrm{M}$ of each dNTP, and $1 \mathrm{U}$ of Taq polymerase (Invitrogen). Thirtyfive cycles of amplification were performed, each cycle consisting of $30 \mathrm{sec}$ denaturation at $96^{\circ} \mathrm{C}, 30 \mathrm{sec}$ annealing at the amplicon specific annealing temperature, and $30 \mathrm{sec}$ elongation at $72^{\circ} \mathrm{C}$. Amplicon specific annealing temperature were $60^{\circ} \mathrm{C}, 60^{\circ} \mathrm{C}, 60^{\circ} \mathrm{C}$, $62^{\circ} \mathrm{C}$, and $65^{\circ} \mathrm{C}$ for $A C T V$, VIM, TERF1, and MTHFD1, respectively. PCR products were purified with Exo-SAP (Amersham) and then directly sequenced on both strands on an ABI PRISM 3100 DNA sequencer (Perkin Elmer-Applied Biosystems) using the Big Dye Terminator method according to the manufacturer's instructions.

Received July 9, 2008; accepted September 2, 2008.

\section{REFERENCES}

Ball, H.J., McParland, B., Driussi, C., and Hunt, N.H. 2002. Isolating vessels from the mouse brain for gene expression analysis using laser capture microdissection. Brain Res. Brain Res. Protoc. 9: 206-213.

Bonner, R.F., Emmert-Buck, M., Cole, K., Pohida, T., Chuaqui, R., Goldstein, S., and Liotta, L.A. 1997. Laser capture microdissection: Molecular analysis of tissue. Science 278: 1481-1483.

Copois, V., Bibeau, F., Bascoul-Mollevi, C., Salvetat, N., Chalbos, P., Bareil, C., Candeil, L., Fraslon, C., Conseiller, E., Granci, V., et al. 2007. Impact of RNA degradation on gene expression profiles: Assessment of different methods to reliably determine RNA quality. J. Biotechnol. 127: 549-559.

Deutscher, M.P. 2006. Degradation of RNA in bacteria: Comparison of mRNA and stable RNA. Nucleic Acids Res. 34: 659-666.

Duggan, D.J., Bittner, M., Chen, Y., Meltzer, P., and Trent, J.M. 1999. Expression profiling using cDNA microarrays. Nat. Genet. 21: 10-14.

Emmert-Buck, M.R., Bonner, R.F., Smith, P.D., Chuaqui, R.F., Zhuang, Z., Goldstein, S.R., Weiss, R.A., and Liotta, L.A. 1996. Laser capture microdissection. Science 274: 998-1001.

Fend, F., Emmert-Buck, M.R., Chuaqui, R., Cole, K., Lee, J., Liotta, L.A., and Raffeld, M. 1999. Immuno-LCM: Laser capture microdissection of immunostained frozen sections for mRNA analysis. Am. J. Pathol. 154: 61-66.

Fleige, S. and Pfaffl, M.W. 2006. RNA integrity and the effect on the real-time qRT-PCR performance. Mol. Aspects Med. 27: 126-139.

Frost, A.R., Eltoum, I.E., and Siegal, G.P. 2001. Laser capture microdissection. In Current protocols in molecular biology, Chap. 25, Sec. A, pp. 25A.1.1-25A.1.24. Wiley, New York.

Goldsworthy, S.M., Stockton, P.S., Trempus, C.S., Foley, J.F., and Maronpot, R.R. 1999. Effects of fixation on RNA extraction and amplification from laser capture microdissected tissue. Mol. Carcinog. 25: 86-91.

Hiller, T., Snell, L., and Watson, P.H. 1996. Microdissection RT-PCR analysis of gene expression in pathologically defined frozen tissue sections. Biotechniques 21: 38-40, 42, 44.

Huang, L.E., Luzzi, V., Ehrig, T., Holtschlag, V., and Watson, M.A. 2002. Optimized tissue processing and staining for laser capture microdissection and nucleic acid retrieval. Methods Enzymol. 356: 49-62.

Imbeaud, S., Graudens, E., Boulanger, V., Barlet, X., Zaborski, P., Eveno, E., Mueller, O., Schroeder, A., and Auffray, C. 2005. Toward standardization of RNA quality assessment using userindependent classifiers of microcapillary electrophoresis traces. Nucleic Acids Res. 33: e56. doi: 10.1093/nar/gni054.

Luo, L., Salunga, R.C., Guo, H., Bittner, A., Joy, K.C., Galindo, J.E., Xiao, H., Rogers, K.E., Wan, J.S., Jackson, M.R., et al. 1999. Gene expression profiles of laser-captured adjacent neuronal subtypes. Nat. Med. 5: 117-122.

Michel, C., Desdouets, C., Sacre-Salem, B., Gautier, J.C., Roberts, R., and Boitier, E. 2003. Liver gene expression profiles of rats treated with clofibric acid: Comparison of whole liver and laser capture microdissected liver. Am. J. Pathol. 163: 2191-2199.

Mikulowska-Mennis, A., Taylor, T.B., Vishnu, P., Michie, S.A., Raja, R., Horner, N., and Kunitake, S.T. 2002. High-quality RNA from cells isolated by laser capture microdissection. Biotechniques 33: 176-179.

Mojsilovic-Petrovic, J., Nesic, M., Pen, A., Zhang, W., and Stanimirovic, D. 2004. Development of rapid staining protocols for laser-capture microdissection of brain vessels from human and rat coupled to gene expression analyses. J. Neurosci. Methods 133: $39-48$.

Schroeder, A., Mueller, O., Stocker, S., Salowsky, R., Leiber, M., Gassmann, M., Lightfoot, S., Menzel, W., Granzow, M., and Ragg, T. 2006. The RIN: RNA integrity number for assigning integrity values to RNA measurements. BMC Mol. Biol. 7: 3.

Sgroi, D.C., Teng, S., Robinson, G., LeVangie, R., Hudson Jr., J.R., and Elkahloun, A.G. 1999. In vivo gene expression profile analysis of human breast cancer progression. Cancer Res. 59: 5656-5661.

Suarez-Quian, C.A., Goldstein, S.R., Pohida, T., Smith, P.D., Peterson, J.I., Wellner, E., Ghany, M., and Bonner, R.F. 1999. Laser capture microdissection of single cells from complex tissues. Biotechniques 26: 328-335.

Wang, H., Owens, J.D., Shih, J.H., Li, M.C., Bonner, R.F., and Mushinski, J.F. 2006. Histological staining methods preparatory to laser capture microdissection significantly affect the integrity of the cellular RNA. BMC Genomics 7: 97.

Yang, H., Xu, Z., Iuvone, P.M., and Grossniklaus, H.E. 2006. Angiostatin decreases cell migration and vascular endothelium growth factor (VEGF) to pigment epithelium derived factor (PEDF) RNA ratio in vitro and in a murine ocular melanoma model. Mol. Vis. 12: 511-517. 

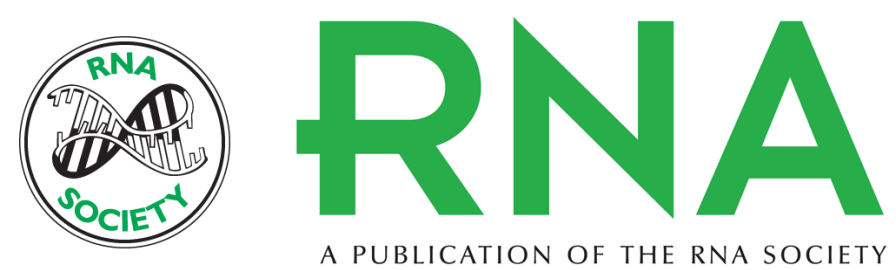

\section{Stabilization of RNA during laser capture microdissection by performing experiments under argon atmosphere or using ethanol as a solvent in staining solutions}

Mathieu Clément-Ziza, Arnold Munnich, Stanislas Lyonnet, et al.

RNA 2008 14: 2698-2704 originally published online October 22, 2008

Access the most recent version at doi:10.1261/rna.1261708

References This article cites 21 articles, 3 of which can be accessed free at:

http://rnajournal.cshlp.org/content/14/12/2698.full.html\#ref-list-1

License

Email Alerting Receive free email alerts when new articles cite this article - sign up in the box at the Service top right corner of the article or click here. 